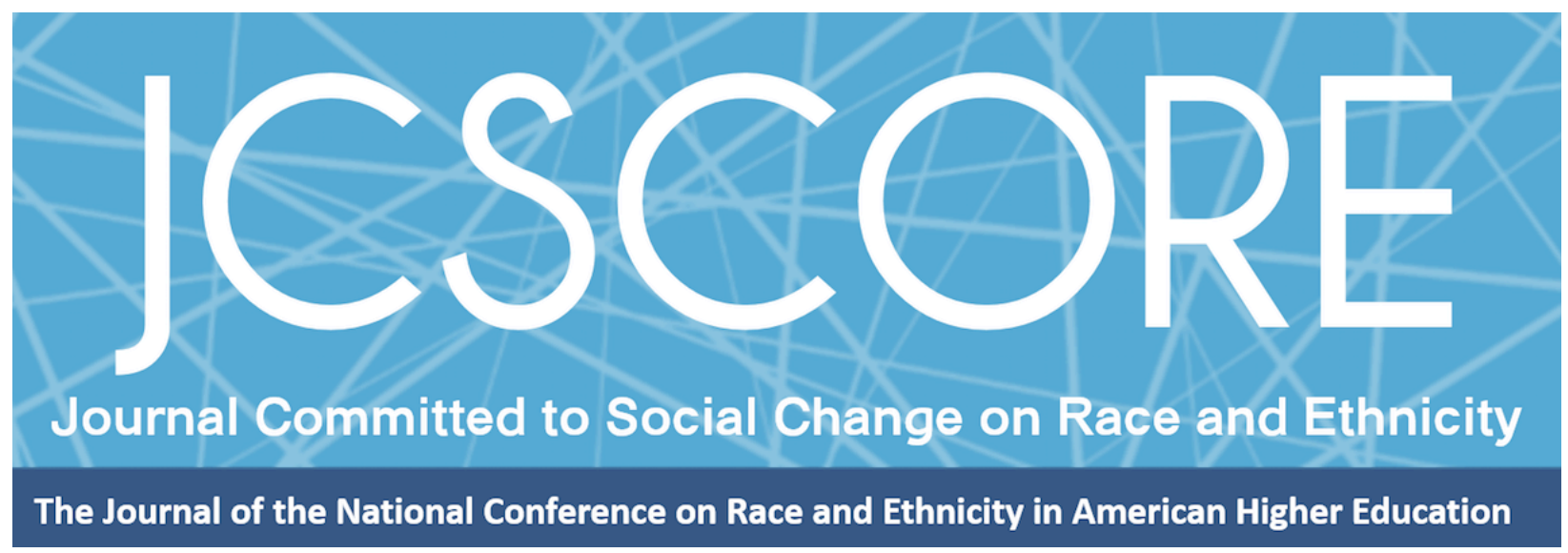

\title{
APPLYING OUR IMAGINATION TO SETTLE UNFINISHED BUSINESS
}

Mitchell J. Chang

University of California, Los Angeles

Journal Committed to Social Change on Race and Ethnicity

Volume 1, Issue 1| 2015

Copyright $\odot 2015$ Board of Regents of The University of Oklahoma on behalf of the Southwest Center for Human Relations Studies.

Permission of the Publisher is required for resale or distribution and for all derivative works, including compilations and translations. Quoting small sections of text is allowed as long as there is appropriate attribution. 


\title{
Applying Our Imagination to Settle Unfinished Business
}

\author{
Mitchell J. Chang \\ University of California, Los Angeles
}

\begin{abstract}
Recent events on colleges campuses specifically and society generally suggest that a new generation of scholars will inherit the unfinished business of resolving our nation's longstanding "race problem." What can a journal do to improve their chances of producing scholarship that will lead to dismantling oppressive racial patterns and order? I argue in this manuscript that JCSCORE should provide more space to exchange and critique imaginations of new racial meanings and structures. Such forward-looking thinking that stretch beyond standardized approaches to scholarship can help coordinate and guide the application of empirical research. After all, "social change" is much more than an empirical project and ultimately requires a creative and organizing vision that inspires, invents, and sustains transformative actions.
\end{abstract}

Can adding another journal to an already overcrowded market of academic journals contribute to accelerating the transformation of higher education? Certainly the Journal Committed to Social Change and Race and Ethnicity (JSCORE) aims to undertake such lofty goals by documenting ways to enhance learning and improve human relations within, across, and through colleges and universities. Perhaps with such a targeted central interest, there is reason to be hopeful that a robust exchange of ideas promoted through this journal can make a meaningful difference in the real world-one that will move the proverbial needle in favor of positive "social change" regarding race and ethnicity. I have been waiting a very long time for scholarship to have this type of inspirational and sustained impact, as I have become increasingly more impatient with the long trail of unfinished business.

I specialize in the study of "diversity" in higher education and focus mainly on racial diversity. I have been contributing to the knowledge base that informs this broad 
set of topics for over two decades. As I move into what will likely be the last leg of my career and as my children enroll in high school, I have noticed myself becoming increasingly more impatient when it comes to social change. I fully expected by now that racial disparities and antipathies would be lessons that my children would read in high school history books rather than learned in the daily news or on the playground. I am reminded almost weekly by what I see in mainstream media and experience in life that race relations and racism may not be significantly better today than it was in my childhood. In some pockets of our nation, circumstances may even be getting worse.

Perhaps my expectations about the speed of change toward improved learning and human relations across racial and cultural differences by eradicating racism were too ambitious and even implausible. Yet, for an Asian American who grew up under the protection of the 1964 Civil Rights Act, those expectations seem realistic and the setbacks have been especially painful. In this essay, I share parts of my life journey to provide a better sense of my expectations and frustrations. This is my way of doing what my Native Hawaiian students describe as "talking story." Staying true to this approach, I do not conform here to conventional scholarly writing styles and purposefully do not list references or footnotes. After all, a story emerges from one's imagination and faded memories, so any lesson to be gained from this essay is more conceptual than factual. I employ this approach so that I can freely point out broader challenges and opportunities for this new journal, which is what I was invited to do. In the end, I hope to offer a few insights to help frame the future of this bold new initiative.

The way I imagine the process and speed of social change related to race and ethnicity has been fundamentally shaped by civil rights legislation. For me, those moves 
made in the sixties are not just topics for academic study but much more personal as they were and continue to be life-changing political acts. One of those federal moves was Title VIII of the Civil Rights Act, the Fair Housing Act, which Congress passed in April 1968, only one week after the assassination of Martin Luther King. This legislation made it unlawful to refuse to sell, rent to, or negotiate with any person because of race, color, religion, sex, or national origin. Fortunately, my family arrived in the U.S. after this legislation was already in effect.

We arrived in San Jose, California from Taiwan in 1971. That city was at the cusp of transforming from a largely rural area to an urban one, eventually becoming the technological capital of the world. Developers were quickly converting farmlands into what would become a suburban sprawl. We eventually settled into a new track development on the Southside of San Jose. Each week, new families moved into this neighborhood as new homes were erected.

That the Fair Housing Act hovered over the development of these new communities that were being built literally from the ground up, allowed for racial diversity in my childhood neighborhood. Next door to us lived an older African American couple, the Pressleys, with a grandson who played with me and other neighborhood kids when he regularly visited for long weekends. From him, we learned that his family came from the east coast and that his father had once played with my favorite basketball team at the time, the Harlem Globetrotters. Next door to this couple lived a Mexican-American family, the Alverez who had a son that I did not know because he was about ten years older, but like me, would later earn a doctorate degree in education. To the other side of us lived an older white couple, the Hildebrand, who owned an auto body shop and next 
to them was another Asian family, the Kong, who were third generation Chinese Americans. Mr. Kong worked as a butcher at a local supermarket and would pass on to his son who was a regular childhood playmate, a love for fishing. Several houses down from them lived a family who were recent immigrants from Denmark, with a boy that would also occasionally play with us and spoke with an accent different from mine. This racial mixing was repeated throughout the block.

To accommodate this growing neighborhood, brand new schools were built at the elementary, middle, and high school levels. Exposure to diversity was an inescapable reality in this community. The school cafeteria, for example, served enchiladas and tacos, prompting me to come home one day and ask my mother to replicate those meals that were considered my favorite "American food." In turn, my mother would cook fried rice or chow mien for my Cub Scout potlucks, which were always well received, and even introduced the group to sushi, which was not as well received. For this newly formed Cub Scout "pack," Admiral Johnston, an active Commanding Naval Officer, served as the Scout Master. My close childhood friends included Silvano Bernardi whose parents were recent Italian immigrants and Doug Tatsui whose U.S. born parents were forced by their own government to spend part of their childhood during WWII in an internment camp in Topaz, Utah.

This small community was not problem-free but faced its own set of challenges regarding race and I still bare the scars of racial harassment and discrimination. Yet, growing up in such an environment impressed upon me that racial diversity was not an abstract idea but a fact of life. My childhood shaped not only my perception of what diversity is but also my expectation of what it can be. So, I had imagined that by now 
Journal Committed to Social Change on Race and Ethnicity | 2015

most communities across the nation would not only be more diverse but would have had enough time to resolve the challenges of such communities. I naively expected this to be the case for my hometown.

I returned to live in San Jose in 1990, seven years after leaving the city to further my education. By then, it was a much bigger version of the one I remembered from my childhood, yet parts of it were still recognizable. Upon my return, I landed a job working for the Alum Rock Elementary School District, which serves a community about five miles from where I grew up. My family used to frequent a popular shopping mall located there but when I started working at Alum Rock, I could no recognize this community because it had been transformed demographically by an influx of both Latino and Southeast Asian immigrants. While the racial composition of a few schools in this district looked similar to the one I once attended, the majority of them were more segregated with either majority Latino, Southeast Asian, or African American students. Those schools with majority students of color were also in the most neglected neighborhoods and faced the toughest educational challenges.

Given the unevenness across schools, this district was one of the first to experiment with vouchers, which promised to provide parents with more and better choices for schooling. I started at the District office shortly after the voucher program was declared a miserable failure for reasons that are now well documented in the literature about such interventions. While working for this district, I observed first hand the social and economic cost of racial segregation and the challenges for schools to overcome those divides. Clearly, my naïve expectations that my hometown would be further along in resolving the "race problem" had not been realized, and instead, it 
seemed that for Alum Rock, circumstances had gotten worse. I also realized that my expectations were clouded by unrecognized privileges that engendered hope instead of despair. The lack of progress troubled me, yet also motivated me to continue my graduate studies. It turned out that further south in the same state, circumstances were indeed getting worse.

In the fall of 1992, I enrolled in a Ph.D. program at University of California, Los Angles (UCLA). Five months before I arrived, a trial jury acquitted four Los Angeles policy officers of assault and use of excessive force in the beating of Rodney King. Following the verdict, the city experienced one of the largest (11,000 arrests) and worst riots (57 deaths) in United States since the 1960's. I had seen similar expressions of anger, frustration, and disillusionment, albeit on a different scale, working in East San Jose. When I started at UCLA, the riots were still very raw and research that addressed the racial divide as experienced economically, socially, culturally, and politically was being elevated rather than ignored. This crisis generated a remarkable interest, energy, and support for addressing racism, which shaped the research conducted by both faculty and graduate students.

Yet, even before I finished my studies, attention was already shifting quickly away from addressing the circumstances that fueled the riots to protecting the gains made by civil rights legislation. In 1993, the University of California Board of Regents proposed $S B$ 1, which prohibited the consideration of race when admitting students in California's public universities and colleges. In 1994, California voters passed a ballot initiative (Proposition 187) that prohibited undocumented individuals from using social services including health care and public education. This initiative was later found by a 
Journal Committed to Social Change on Race and Ethnicity | 2015

federal court in 1999 to be unconstitutional. The discourse on race in Los Angeles shifted even further away from the 1992 riots when OJ Simpson was arrested in 1994 for the murder of his ex-wife. By the time I graduated from UCLA, those concerns that were triggered by the riots and subsequently galvanized efforts to address overlooked racial problems were but distant memories buried under Simpson's 1995 acquittal and the passing of Proposition 209 in 1996, which prohibited California governmental institutions, including public universities and colleges, to consider race, sex, or ethnicity in employment, contracting, and education.

When I returned to UCLA in 1999 to begin a faculty appointment, there were fewer African American and Latino students enrolled than when I was there as a graduate student. Department colleagues were still recovering from the fight over Proposition 227, a California ballot initiative that passed in 1998 and significantly limited bilingual education and were gearing up to oppose another ballot measure, Proposition 54. Billed as the "Racial Privacy Initiative," this proposition would limit the collection of racial data and would have significantly weakened the state's capacity to track racial disparities across key educational, economic, and housing indicators had it passed (defeated in 2003). With so many recurring challenges to gains made by previous civil rights initiatives, the racial crisis observed in 1992 was being settled not by sustained intervention but by manufactured amnesia.

Given the many political battles waged across the state, today's graduate students at UCLA grapple with the same issues concerning racial disparities and antipathies that my classmates and I grappled with twenty years ago in the same building. While there are now more empirical studies and better methods to guide their 
Journal Committed to Social Change on Race and Ethnicity | 2015

inquiries, those students inherited the unfinished business of my generation and continue to examine how race shapes educational opportunities and experiences in ways that reinforce and even exacerbate disparities across key social, political, and economic indicators. That the same problems and issues that had perplexed me as a graduate student at UCLA continue to reverberate within the same building for current graduate students, contributes to my mounting impatience with the progress of social change.

Thus, I welcome the launch of JCSCORE and look forward to learning from it in hopes of easing my impatience. Yet as I sit here writing this essay, the Baltimore Orioles are playing the Chicago White Sox in an empty ballpark. This unprecedented event has never occurred in the 140 years of Major League baseball. The game at Camden Yards located in downtown Baltimore was closed to the public due to concerns raised by surrounding riots that began after the funeral of an African American man who died while in police custody. This is another of many reminders in the last two years of our nation's ugly racial legacy. Recently, such ugly incidents were repeated in cities as small as Ferguson, MO and as large as Baltimore, MD. They also took place recently on our institutions of higher education from the University of Alabama whereby a member of the Chi Omega sorority took a "selfie" on bid day and allegedly included the caption, "Chi O got NO niggas!!!!" to the University of Oklahoma whereby members of the Sigma Alpha Epsilon fraternity proudly sang "There will never be a nigger in SAE." How can a journal end this cycle of ignorance, hate, anger, and pain? Will another generation of scholars inherit our unfinished business?

I do not think that the failure to advance "social change" and settle a long trail of 
unfinished business is centrally an intellectual or empirical failure. The growth of The National Conference of Race and Ethnicity (NCORE) and the start of this journal are just two of many examples suggesting that there are increasing interest in and growth of the knowledge base. I know first hand that since the 1992 unrest in Los Angeles, scholars and practitioners have established important insights, grounded in rigorous empirical research published across a wide range of "high impact" journals. Yet, another generation of youths is stuck in failed schools and neglected neighborhoods, leaving them with little hope for the future despite those significant intellectual gains.

Perhaps the persistence of the problems we face today suggest that the rich body of scholarship and research that inform race has not yet reached broadly or deeply enough to make a meaningful difference. If so, there is a vital yet overlooked problem regarding the application of the already rich body of scholarship. In applying research, there are countless issues that are outside of a journal's direct control, including negotiating political forces and obtaining adequate resources to launch empirically informed efforts. Still, journals can do more to move the needle toward more positive social change and I will highlight two moves that might be helpful for framing JCSCORE.

First, encourage forward thinking scholarship. In his groundbreaking analysis of scientific research, Thomas Kuhn observed that as a body of research advances, the knowledge base necessarily becomes more specialized and those contributing to it become increasingly more likely to work within a well-defined set of assumptions or a "paradigm." This type of knowledge accumulation promotes a tendency within its community of scholars to look inward within itself to build a mountain of empirical 
evidence rather than outward to make the knowledge applicable to society. In other words, a journal can end up fixating our gaze inwardly onto the scholarship for its own sake at the expense of gazing outwardly to solve real world problems. While advancing knowledge in systematic and rigorous ways is extremely important, the market is already crowded with such journals that appeal to those who fixate their gaze inwardly and conduct their research primarily for their insular intellectual community. Fewer journals gaze outwardly beyond a specialized audience, particularly when it comes to scholarship that addresses race, and offer forward thinking application of scholarship that can disrupt what Lori Patton at Indiana University calls the ordinary, predictable and taken for granted ways in which the academy functions as a bastion of racism/white supremacy and overall inequality.

In order to be forward thinking, however, a journal needs to create more space for imagination that, according to Ana M. Martinez-Aleman at Boston College, can move us toward a more cohesive approach to challenging norms, questioning legitimacy of dominant arrangements, and offering alternative structures and practices. Publications that gaze inwardly have already limited their capacity for imagination because they operate under what Brian Pusser at the University of Virginia argues are norms and assumptions settled by historical agreement, including how to conduct research and what counts as noteworthy scholarship. Given how I approached this essay, for example, it could not be published in most academic journals because it does not conform to their strict format for scholarly discourse. Yet in order to apply research, according to the sociologist $\mathrm{C}$. Wright Mills, we must be guided by a bigger vision and purpose, which stretches standardized approaches to scholarship. That is, our capacity 
Journal Committed to Social Change on Race and Ethnicity | 2015

to address real world problems benefits from scholarship that both documents what is happening in the real world and also imagines a better future world in ways that are not bounded by dominant forms of scholarship. While the former is already well aligned with familiar journals, the latter is rare but necessary because it pushes us to be more forward-looking by projecting a vision that guides the application and organization of research toward a purposeful direction.

By no means should the aim here be to embrace only one way of imagining racial meaning and structure, but to provide opportunities to examine carefully and to critique vigorously the multiple and competing visions that can guide the application of research. I fully recognize that one's imagination is shaped by privileges that obscure deeply rooted problems. This ensures, however, that there will be competing visions and historically, such has been the case for guiding the application of research. Take for example the competing visions between W.E.B DuBois and Booker T. Washington, and between Martin Luther King and Malcom X. Each applied his own unique background, personal experiences, disciplinary learning, and theoretical/philosophical orientation to imagine a pathway to racial justice. There seems to be little room in the small set of journals that I frequent for such a sharing of imagination that breaks away from traditional approaches to scholarship yet can still guide our empirical and practical work.

This robust exchange of imaginations can also inform other powerful forces that can more broadly shape our nation's imagination. Unfortunately, what I typically see from one of those powerful forces, mainstream news, tends to fuel our fears and divide more than it raises our hopes and unite. Forces that limit our thinking and imagination replay tired stereotypes that reduce our capacity both to see a wider range of 
Journal Committed to Social Change on Race and Ethnicity | 2015

perspectives within a single category and to act toward individuals unlike us with greater empathy. Operating with such hardened and narrow outlooks further increases the tendency to reject and ignore certain facts that are inconsistent with one's narrow view of different groups in particular and the world in general. Kevin Kumashiro at the University of San Francisco refers to such actions as willful ignorance, which by definition is unaffected by interceding with empirical evidence alone. Perhaps, we should also give imagination a chance to invent new forms of social and collective possibilities that can begin to expand narrow visions that have been hardened by willful ignorance.

A forward looking journal that makes room for imagination would also make clearer that "social change" is much more than an empirical project but one that ultimately requires inspiring, inventing, and sustaining transformative actions. Accordingly, we must examine both the science that illuminates racial meaning and structures on the one hand and the art of rearranging meaning and inventing structures on the other hand. Whereas the former is steered by attention to a method of inquiry that builds upon existing knowledge, the latter is steered by attention to a philosophy of inquiry that broadens existing practices. Expanding our approaches to rigorous inquiry in ways that blend the world of scientific absolutes, applied approximations, and social imaginations can challenge readers to enter different spheres of knowledge, which in turn provides them with a more complete picture of social action and change.

\section{Conclusion}

While the story that I highlighted above suggests that social change has not met my expectations as a middle-aged man who emigrated to the U.S. as a child and who 
Journal Committed to Social Change on Race and Ethnicity | 2015

grew up in a racially diverse neighborhood, I also fully recognize and very much appreciate the changes that have been made. A document that I received upon purchasing a home is pinned up on a corkboard in my office, reminding me that my life today would be very different if our nation had not made giant strides in addressing racism over the past fifty years. This real estate document outlines the covenant, conditions, and restrictions (CC\&Rs) for my family's current neighborhood. Within the "Restrictions" section, Item \#7 states:

"That neither the whole nor any part of said premises shall be sold, rented or leased to any person of Ethiopian, Chinese or Japanese descent, nor shall the same be occupied or used by any such person except as a servant or employee of the person using said premises exclusively for residential purposes..."

This CC\&R was first approved in February 12, 1946 but the above paragraph was not officially overturned until Dec 31, 1973. If residents had actually enforced this paragraph until it was officially eliminated, they would have been in violation of the Fair Housing Act, rendering it impossible for me to have lived here when I immigrated to the U.S. Despite such past measures, my family has made this community our home for nearly two decades-a community that once prohibited people like me from living here.

Also, the fact that I even have an office at UCLA to pin up such a document also suggests to me that things have changed for the better. When I was hired, my specific academic unit had no faculty of color on tenure track and had never hired an Asian American scholar, let alone one interested in examining issues of race in higher education. This program was situated within a department that had denied tenure to the 
Journal Committed to Social Change on Race and Ethnicity | 2015

last Asian American faculty member who went through the department's promotion process. Now, our department and program has among the most racially diverse faculty of any department at UCLA. Although my current students are concerned about and address issues similar to those that I did as a graduate student, they now have courses and faculty that help them engage in these issues in more intense ways that were unavailable to me in the early nineties.

Indeed, remarkable transformations are occurring across our nation's colleges and universities, producing more complex racial dynamics and shifting racial meaning and identities. Researchers are grappling with the implications of these transformations for social policy, political processes, civic participation, and cultural life. Yet, in an effort to make sense of this transformation and how it is shaped by and reshaping the meaning and structure of race, it is important to have a publication outlet that engages forward-looking discourse that draws not only from traditional scholarship but also from imaginations shaped by rich lived experiences in unique contexts. Perhaps JCSCORE can add more value to the already rich array of available journals by both documenting racial dynamics and order as they currently exist and also offering new forms of knowing, seeing, and imagining the significance of race in what Howard Winant, the Director of the University of California Center for New Racial Studies, calls the post-Civil Rights era, the post-colonial era, the post-apartheid era, and the soon to be post Obama era.

Perhaps this one small move to free our imagination from the shackles of academic norms and focus on looking forward beyond methodological inquiry and into applied philosophical inquiry can increase the likelihood that the next generation of 
Journal Committed to Social Change on Race and Ethnicity | 2015

scholars will be addressing new issues rather than the unfinished business from my generation. Although we are still far off from settling the unfinished business as evidenced by recent events, I'm actually quite optimistic that my imagination shaped by the diverse communities that I have inhabited will be realized within my life time and that the next generation of scholars will invent new relationships and structures that are beyond my own imagination.

In late April 2015, my youngest child who is completing his last year at the UCLA Lab School, was assigned to give a short presentation about himself. This was a part of a larger sixth grade culmination project assigned to all students in his grade level. Parents were invited to attend the presentations and I was struck by the diversity within my son's class. Of the twenty-four students who presented, only two came from families whereby both parents were at least third generation U.S. citizens with European roots. The rest had at least one parent who did not have European ancestry and half of the students had parents who spoke a language other than English at home. There were six students who considered themselves "multi-racial" and two who were adopted from another country and do not share the same race as their parents. No doubt this school is atypical and benefits from its affiliation with the university. Still, it reflects the population of Los Angeles both demographically and economically, which is an important aspect of this school's charter.

I doubt, however, that the diversity of Los Angeles converge into many schools the way it does at UCLA's labs school. Yet, for those who grew up in such an environment, they will have very different expectations of and imaginations about racial diversity. If DuBois, Washington, King, or Malcom X had lived such a reality, I wonder 
Journal Committed to Social Change on Race and Ethnicity | 2015

how they would have imagined the future? Even if those imaginations were marked by privileges that obscure other hardships, as is often the case with scholarly publications, they would still be noteworthy ideas of possibilities. Unfortunately, much of what I read in academic journals tend to be narrowly focused and fragmented, without an organizing social or moral horizon that maximizes the application of research and mobilizes solidarity. As Vijay Prashad of Trinity College noted recently in his keynote at the University of California Center for New Racial Studies (UCCNRS) conference, our role as scholars and intellectuals is not to produce knowledge but to move the course of history. Will JCSCORE facilitate our capacity to move history? 